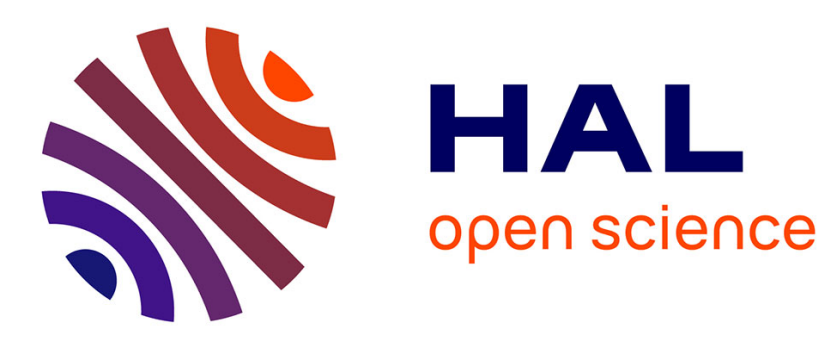

\title{
Ionic Exchange of Metal-Organic Frameworks for Constructing Unsaturated Copper Single-Atom Catalysts for Boosting Oxygen Reduction Reaction
}

Shenghua Ma, Zheng Han, Kunyue Leng, Xiaojie Liu, Yi Wang, Yunteng Qu, Jinbo Bai

\section{To cite this version:}

Shenghua Ma, Zheng Han, Kunyue Leng, Xiaojie Liu, Yi Wang, et al.. Ionic Exchange of MetalOrganic Frameworks for Constructing Unsaturated Copper Single-Atom Catalysts for Boosting Oxygen Reduction Reaction. Small, 2020, 16 (23), pp.2001384. 10.1002/smll.202001384 . hal-03414478

\author{
HAL Id: hal-03414478 \\ https://hal.science/hal-03414478
}

Submitted on 4 Nov 2021

HAL is a multi-disciplinary open access archive for the deposit and dissemination of scientific research documents, whether they are published or not. The documents may come from teaching and research institutions in France or abroad, or from public or private research centers.
L'archive ouverte pluridisciplinaire HAL, est destinée au dépôt et à la diffusion de documents scientifiques de niveau recherche, publiés ou non, émanant des établissements d'enseignement et de recherche français ou étrangers, des laboratoires publics ou privés. 
Ionic Exchange of Metal-Organic Frameworks for Constructing Unsaturated Copper Single Atom Catalysts for Boosting Oxygen Reduction Reaction

Shenghua Ma, Zheng Han, Kunyue Leng, Xiaojie Liu, Yi Wang*, Yunteng Qu* and Jinbo $B a i^{*}$

S. Ma, Z. Han, K. Leng and Dr. Y. Wang

Institute of Photonics \& Photon-Technology, Northwest University, Xi'an, 710069, China. E-mail: yi.wang@nwu.edu.cn

Dr. X. Liu

College of Chemistry \&Materials Science, Northwest University, Xi'an, 710069, China.

Dr. Y. Qu

Department of Chemistry, Hefei National Laboratory for Physical Sciences at the Microscale, iChEM (Collaborative Innovation Center of Chemistry for Energy Materials), University of Science and Technology of China, Hefei, 230026, China.

E-mail: quyt@ustc.edu.cn

Prof. J. Bai

Lab. MSSMat, CNRS UMR 8579, Ecole CentraleSupélec, Université Paris-Saclay, 8-10 rue Joliot-Curie, 91190, Gif-sur-Yvette, France.

E-mail: jinbo.bai@centralesupelec.fr

Keywords: single atom, copper, unsaturated coordination, oxygen reduction reaction

Regulating the coordination environment of atomically dispersed catalysts is vital for catalytic reaction but still remains challenge. Herein, an ionic exchange strategy has been developed to fabricate atomically dispersed copper catalysts with controllable coordination structure. In this process, the adsorbed $\mathrm{Cu}$ ions exchange with $\mathrm{Zn}$ nodes in $\mathrm{ZIF}-8$ under high temperature, resulting in the trapping of $\mathrm{Cu}$ atoms within the cavities of the MOF and thus forming $\mathrm{Cu}$ single atom catalysts. More importantly, altering pyrolysis temperature can effectively control the structure of active metal center at atomic level. Specifically, higher treatment temperature $\left(900{ }^{\circ} \mathrm{C}\right)$ leads to unsaturated copper-nitrogen architecture $\left(\mathrm{Cu}-\mathrm{N}_{3}\right.$ moieties $)$ in atomically dispersed $\mathrm{Cu}$ catalysts. Electrochemical test indicates atomically dispersed $\mathrm{Cu}$ catalysts with $\mathrm{Cu}-\mathrm{N}_{3}$ moieties possess superior ORR performance than that with higher copper-nitrogen coordination number $\left(\mathrm{Cu}-\mathrm{N}_{4}\right.$ moieties), with a higher half-wave potential of $180 \mathrm{mV}$ and the 10 times turnover frequency than that of $\mathrm{CuN}_{4}$. DFT calculation analysis further shows that the low $\mathrm{N}$ coordination number of $\mathrm{Cu}$ single atom catalysts $\left(\mathrm{Cu}-\mathrm{N}_{3}\right)$ is favorable to the formation of $\mathrm{O}_{2} *$ intermediate and thus boosts the oxygen reduction reaction. 
Searching for platinum free catalysts to overcome the sluggish kinetics of oxygen reduction reaction (ORR) at the cathode was the key to realize large-scale application of metal-air batteries and proton-exchange membrane fuel cells. ${ }^{[1-6]}$ Owing to their cost-effective and high-performance, transition metals single atom with $\mathrm{N}$-doped carbon materials (M SAs/NC) were recognized as one of the most promising candidates. ${ }^{[7-15]}$ The local coordination environment of M SAs/NC generally played a significant role for the catalytic activity and selectivity. ${ }^{[4,16-19]}$ However, precisely regulating the coordination environment of active center in M SAs/NC still remains challenges due to the high mobility and instability of highly dispersed single metal atoms.

Copper metalloenzymes with unsaturated $\mathrm{Cu}-\mathrm{N}$ centers have been demonstrated to efficiently active oxygen molecular at low overpotentials. ${ }^{[20,21]}$ Recently, $\mathrm{CuN}_{3}$ moieties supported on carbon matrix was also reported as efficient ORR catalysts, further corroborating the high ORR activity for unsaturated $\mathrm{Cu}-\mathrm{N}$ centers with charge density asymmetry. ${ }^{[22]}$ And, copper single atom ORR catalysts have attracted much attention. ${ }^{[22-27]}$ However, the rational design and efficient construction of atomically dispersed $\mathrm{Cu}$ catalysts with unsaturated centers remained imperative and challenging. In this work, we adopt an ionic exchange method to construct unsaturated copper single atom catalysts. Under high temperature, the adsorbed copper ion was trapped in the defective sites derived from the volatile Zn nodes in ZIF-8, thus forming $\mathrm{Cu}$ single atom catalysts. ${ }^{[28]}$ Altering the treatment temperature could effectively regulate the coordination structure of $\mathrm{Cu}$ sites in atomic level. For example, the $\mathrm{CuN}_{3}$ and $\mathrm{CuN}_{4}$ coordination structures were prepared at 900 and $800{ }^{\circ} \mathrm{C}$, respectively. The corresponding material was labelled as $\mathrm{Cu}$ SAs/NC-900 and Cu SAs/NC-800, respectively. Moreover, $\mathrm{Cu}$ SAs/NC-900 with unsaturated $\mathrm{Cu}-\mathrm{N}_{3}$ moieties exhibited exceptional ORR activity and superior $\mathrm{Zn}$-air battery performance. 
As shown in Figure S1, ZIF-8 exhibited a rhombododecaheral shape with a smooth surface. Most of the particle size was about $200 \mathrm{~nm}$. Cu SAs/NC-800 and Cu SAs/NC-900 maintained the rhombododecaheral shape with a smaller particle size of about $100 \mathrm{~nm}$ (Figure S2), probably due to the thermal shrinkage of ZIF-8, which could be also observed in pyrolyzed ZIF-8 (NC-900) (Figure S3). Notably, more pores architecture could be observed in $\mathrm{Cu}$ SAs/NC-900 than in $\mathrm{Cu}$ SAs/NC-800. This might be attributed to the higher pyrolysis temperature, which induced the volatilization of more proposed $\mathrm{CN}_{\mathrm{x}}$ fragment. ${ }^{[29]}$ Figure $\mathrm{S} 4$ showed the $\mathrm{N}_{2}$-sorption isotherms, and the detailed sorption data were collected in Table $\mathrm{S} 1$. ZIF-8 showed a BET surface area of $1184 \mathrm{~m}^{2} \mathrm{~g}^{-1}$. After pyrolysis, the BET surface area was decreased to $673 \mathrm{~m}^{2} \mathrm{~g}^{-1}$ for $\mathrm{Cu}$ SAs/NC-800 and $733 \mathrm{~m}^{2} \mathrm{~g}^{-1}$ for Cu SAs/NC-900.

Figure 1 showed the high-angle annular dark-field transmission electron microscope (HAADF-TEM) images of $\mathrm{Cu}$ SAs/NC materials coupled with electron energy loss spectroscopy (EELS). It could be observed that $\mathrm{Cu}$ and $\mathrm{N}$ were homogeneously dispersed over $\mathrm{Cu} \mathrm{SAs/NC-800} \mathrm{(Figure} \mathrm{1A)} \mathrm{and} \mathrm{Cu} \mathrm{SAs/NC-900} \mathrm{(Figure} \mathrm{1C).} \mathrm{Aberration-corrected}$ high-angle annular dark-field scanning transmission electron microscopy (HAADF-STEM) images of Cu SAs/NC-800 (Figure 1B) and Cu SAs/NC-900 (Figure 1D) further revealed that copper was atomically dispersed. The size of bright spots in both $\mathrm{Cu}$ SAs/NC-800 and $\mathrm{Cu}$ SAs/NC-900 were about $1.24 \AA$, according to the corresponding intensity profiles (Figure 1, Figure S5 and Figure S6), in line with the reported size of single copper sites. ${ }^{[23]}$

In the powder X-ray diffraction (XRD) patterns, only one broad peak in the ranges of 20$30^{\circ}$ could be observed (Figure S7), corresponding to the (002) planes of carbon. ${ }^{[18]}$ No $\mathrm{Cu}$ characteristic peaks could be observed in $\mathrm{Cu}$ SAs/NC materials, indicating the poor crystallinity of copper. Figure S8 showed the survey scan X-ray photoelectron spectroscopy (XPS) spectra of $\mathrm{Cu}$ SAs/NC materials. The proportion of copper was nearly identical for $\mathrm{Cu}$ SAs/NC-800 and $\mathrm{Cu}$ SAs/NC-900, in agreement with the result of ICP-OES (Table S1). Figure 2 showed the corresponding $\mathrm{C} 1 \mathrm{~s}, \mathrm{~N} 1 \mathrm{~s}$ and $\mathrm{Cu} 2 \mathrm{p}$ XPS spectra of $\mathrm{Cu}$ SAs/NC 
materials. The peaks at 284.4, 285.6 and $287.8 \mathrm{eV}$ in the $\mathrm{C} 1 \mathrm{~s}$ spectrum (Figure 2A) could be assigned to $\mathrm{C}-\mathrm{C}, \mathrm{C}=\mathrm{N}$ and $\mathrm{C}-\mathrm{N}$, respectively. ${ }^{[22,23]}$ Four peaks at 398.3, 399.8, 400.9, and $402.3 \mathrm{eV}$ were corresponding to pyridinic-N, pyrrolic-N, graphitic-N, and oxide- $\mathrm{N}$, respectively (Figure 2B). ${ }^{[15]}$ The $\mathrm{Cu} 2 \mathrm{p}_{3 / 2}$ peak for both $\mathrm{Cu}$ SAs/NC-800 and Cu SAs/NC-900 was situated at around $933 \mathrm{eV}$ (Figure 2C), which located between $\mathrm{Cu}^{0}$ and $\mathrm{Cu}^{2+}$, and was similar to the reported value for atomically dispersed $\mathrm{Cu}-\mathrm{N}-\mathrm{C}$ material. ${ }^{[23]}$ It should be noticed that the $\mathrm{Cu} 2 \mathrm{p}_{3 / 2}$ peak for $\mathrm{Cu}$ SAs/NC-900 seemed slightly more negative compared with $\mathrm{Cu}$ SAs/NC-800.

X-ray absorption fine structure (XAFS) spectroscopy was used to clarify the detailed structural information of copper atoms. $\mathrm{Cu}$ k-edge XANES spectra of $\mathrm{Cu}$ foil, $\mathrm{CuO}$ and $\mathrm{Cu}$ $\mathrm{SAs} / \mathrm{NC}$ materials (Figure 2D) revealed that the adsorption edge of $\mathrm{Cu}$ SAs/NC materials was between copper foil and $\mathrm{CuO}$, revealing the partial positive charge of copper atoms in $\mathrm{Cu}$ SAs/NC materials. Moreover, the white-line intensity of $\mathrm{Cu}$ SAs/NC-900 was lower than that of $\mathrm{Cu}$ SAs/NC-800, revealing the lower valence state of copper atoms for $\mathrm{Cu}$ SAs/NC-900, which confirmed the XPS results. The EXAFS spectrum (Figure 2E) revealed that copper atoms in $\mathrm{Cu}$ SAs/NC-800 and $\mathrm{Cu}$ SAs/NC-900 formed isolated $\mathrm{Cu}-\mathrm{N}$ coordination structure. This was because that the main peak was situated at about $1.48 \AA$, corresponding to the $\mathrm{Cu}-\mathrm{N}$ coordination. ${ }^{[23,24]}$ Furthermore, no peak at $2.2 \AA$ was detected, which was corresponding to the $\mathrm{Cu}-\mathrm{Cu}$ coordination. In comparison, the interatomic distance of $\mathrm{Cu}-\mathrm{N}$ and the intensity of the main peak in $\mathrm{Cu}$ SAs/NC-900 were reduced compared with that of $\mathrm{Cu}$ SAs/NC-800, suggesting the lower coordination number for $\mathrm{Cu}$ SAs/NC-900. The EXAFS spectrum of $\mathrm{Cu}$ SAs/NC-800 and $\mathrm{Cu}$ SAs/NC-900 was further fitted by possible $\mathrm{Cu}-\mathrm{N}$ coordination structures. As a result, the spectrum of $\mathrm{Cu}$ SAs/NC-800 and $\mathrm{Cu}$ SAs/NC-900 was well fitted by $\mathrm{CuN}_{4}$ and $\mathrm{CuN}_{3}$ coordination structure, respectively (Figure 2F). Table $\mathrm{S} 2$ showed the phase corrected interatomic distance of $\mathrm{Cu}-\mathrm{N}$ for $\mathrm{Cu}$ SAs/NC-800 (1.98 $\AA$ ) and Cu SAs/NC-900 (1.96 $\AA$ ), which was consistent with the reported value for $\mathrm{CuN}_{4}\left(1.98 \AA{ }^{[23]}\right.$ and $\mathrm{CuN}_{3}(1.95$ 
$\AA{ }^{[22]}$. Such a phenomenon was also observed in the study of atomically dispersed Ni-N-C materials, in which the interatomic distance of $\mathrm{Ni}-\mathrm{N}$ for $\mathrm{NiN}_{3}$ was slightly decreased compared with $\mathrm{NiN}_{4}{ }^{[18]}$ Under higher temperature, we supposed that partial of nitrogen was removed, resulting in the formation of $\mathrm{Cu}$ SAs/NC with $\mathrm{CuN}_{3}$ moieties (Figure 2G). In this case, the valence state of copper atoms was slightly decreased, due to the loss of one nitrogen coordination.

The ORR performance of $\mathrm{Cu}$ SAs/NC-800, Cu SAs/NC-900 and references was firstly evaluated through linear sweep voltammetry (LSV) technology in $0.1 \mathrm{M} \mathrm{KOH}$ at $\mathrm{O}_{2}$ saturated condition (Figure 3). The NC reference catalysts exhibited extremely poor activity compared with $\mathrm{Cu}$ SAs/NC materials (Figure 3A and Figure S9), which showed the ORR activity mainly stemmed from $\mathrm{Cu}$ metal sites rather than $\mathrm{NC}$ supports and other elements. Moreover, $\mathrm{Cu}$ SAs/NC-900 exhibited much better activity than $\mathrm{Cu}$ SAs/NC-800, the half-wave potential $\left(\mathrm{E}_{1 / 2}\right)$ and the onset potential of $\mathrm{Cu}$ SAs/NC-900 was much higher than that of $\mathrm{Cu}$ SAs/NC800. The detailed data were collected in Figure 3B. The half-wave potential of $\mathrm{Cu}$ SAs/NC900 was measured at $0.87 \mathrm{~V}, 180 \mathrm{mV}$ higher than that of $\mathrm{Cu}$ SAs/NC-800. At $0.9 \mathrm{~V}, \mathrm{Cu}$ SAs/NC-900 displayed a kinetic current density $\left(\mathrm{J}_{\mathrm{k}}\right)$ at $2.74 \mathrm{~mA} \mathrm{~cm}{ }^{-2}$, which was significantly higher than $\mathrm{Cu}$ SAs/NC-800 (0.21 mA cm $\left.\mathrm{cm}^{-2}\right)$. As shown in Figure 3C, Cu SAs/NC-900 exhibited a lower Tafel slope $\left(79 \mathrm{mV} \mathrm{dec}^{-1}\right)$ than $\mathrm{Cu}$ SAs/NC-800 (122 $\left.\mathrm{mV} \mathrm{dec}^{-1}\right)$, further demonstrated the much higher activity of Cu SAs/NC-900 than Cu SAs/NC-800. Figure S10 showed the polarization curves of $\mathrm{Cu}$ SAs/NC-900 at various rotation rates and the KouteckyLevich (K-L) plots, in which the electron transfer number (n) was calculated at 3.91. The rotating ring-disk electrode (RRDE) test confirmed the near 4-electron ORR pathway for $\mathrm{Cu}$ SAs/NC materials (Figure 3D). The turnover frequency (TOF) of SAs/NC-900 at $0.9 \mathrm{~V}$ was calculated at $0.16 \mathrm{~Hz}$, which was more than 10 times as that of $\mathrm{Cu}$ SAs/NC-800 $(0.015 \mathrm{~Hz})$. These results above provided strong evidence that unsaturated copper single atom catalysts possessed better oxygen reduction reaction activity than $\mathrm{Cu}$ SACs with $\mathrm{CuN}_{4}$ moieties. 
Importantly, the ORR activity of $\mathrm{Cu}$ SAs/NC-900 also outperformed the commercial Pt/C (Figure 3A-C) and most of the reported high-performance noble metal-free ORR catalysts (Table S3).

The electrochemical stability of Cu SAs/NC-900 was tested based on the electrochemical accelerated durability test (EADT) and chronoamperometry. After the 5000 cycles of EADT (Figure S11), no significant activity decay could be observed in $\mathrm{E}_{1 / 2}$. In the long-term stability test at $0.65 \mathrm{~V}$ (Figure S12), Cu SAs/NC-900 lost $7 \%$ of the original current after $10000 \mathrm{~s}$, while around $40 \%$ attenuation of the original current could be observed for Pt/C. These results revealed the strong electrochemical stability of $\mathrm{Cu}$ SAs/NC-900 in alkaline media, which could be attributed to the stable $\mathrm{Cu}-\mathrm{N}_{3}$ coordination structure. The HAAD-STEM confirmed that copper atoms in Cu SAs/NC-900 could remain atomically dispersed after the durability test (Figure S13). The EXAFS results further revealed that the $\mathrm{Cu}-\mathrm{N}$ coordination structure was not modified after test (Figure S14). Furthermore, a zinc-air (Zn-air) battery test was carried out using the zinc foil as the anode and $\mathrm{Cu}$ SAs/NC-900 coated carbon paper as the air cathode. The specific capacity of Cu SAs/NC-900 based Zn-air battery was 712 mAh $\mathrm{g}^{-1}$ at the discharge of $50 \mathrm{~mA} \mathrm{~cm}{ }^{-2}$ (Figure 3E), which was superior to the $\mathrm{Pt} / \mathrm{C}$ based $\mathrm{Zn}$-air battery $\left(608 \mathrm{mAh} \mathrm{g}^{-1}\right)$. In addition, Figure $3 \mathrm{~F}$ shows the discharge polarization and the corresponding power density plots of $\mathrm{Cu}$ SAs/NC-900 and Pt/C based Zn-air battery. The maximum power density of $\mathrm{Cu}$ SAs/NC-900 based Zn-air battery was $242 \mathrm{~mW} \mathrm{~cm}{ }^{-2}$, higher than that of the Pt/C-based $\mathrm{Zn}$-air battery $\left(192 \mathrm{~mW} \mathrm{~cm}^{-2}\right)$ and most of the reported catalysts (Table S4), again verifying the excellent activity of $\mathrm{Cu}$ SAs/NC-900 in ORR.

The significant different ORR activity of Cu SAs/NC-900 and Cu SAs/NC-800 should be mainly attributed to the different nature of $\mathrm{CuN}_{3}$ and $\mathrm{CuN}_{4}$. Therefore, the free energy diagrams of $\mathrm{CuN}_{3}$ and $\mathrm{CuN}_{4}$ in $\mathrm{ORR}$ processes were calculated at different overpotentials (Figure 4). Figure 4A and Figure 4C showed the optimized structure of the models, adsorbed $\mathrm{OOH}, \mathrm{O}$ and $\mathrm{OH}$, over the proposed $\mathrm{CuN}_{4}$ and $\mathrm{CuN}_{3}$, respectively. For $\mathrm{CuN}_{4}$, all reaction 
procedures were thermodynamically downslope, except the $\mathrm{O}_{2}$ adsorption step (Figure 4B), suggesting that the $\mathrm{O}_{2}$ adsorption was the rate-determining step for the oxygen reduction on $\mathrm{CuN}_{4}$, in agreement with previous reports ${ }^{[24]}$. Despite similar tendency was observed over $\mathrm{CuN}_{3}$, the $\mathrm{O}_{2}$ adsorption upslope for $\mathrm{CuN}_{3}(0.17 \mathrm{eV}$, Figure 4D) was much weaker than that of $\mathrm{CuN}_{4}(0.87 \mathrm{eV})$, demonstrating the origin of the high ORR activity for Cu SAs/NC-900. In addition, the $\mathrm{O}_{2}$ adsorption upslope for $\mathrm{NC}$ materials and the $\mathrm{OH}^{*}$ formation upslope for $\mathrm{Pt}$ (111) surface in alkaline solution was about 2.1 and $0.65 \mathrm{eV}$, respectively. ${ }^{[24,30]}$ These results well fitted our experimental findings.

In summary, an ionic exchange strategy was developed to fabricate atomically dispersed $\mathrm{Cu}-\mathrm{N}-\mathrm{C}$ material with unsaturated $\mathrm{Cu}-\mathrm{N}$ centers $\left(\mathrm{Cu}-\mathrm{N}_{3}\right.$ moieties $)$. Electrochemical test indicated that atomically dispersed $\mathrm{Cu}-\mathrm{N}-\mathrm{C}$ material with $\mathrm{Cu}-\mathrm{N}_{3}$ moieties possess superior ORR performance than atomically dispersed $\mathrm{Cu}-\mathrm{N}-\mathrm{C}$ material with $\mathrm{Cu}-\mathrm{N}_{4}$ moieties, with a higher half-wave potential of $180 \mathrm{mV}$ and the 10 times turnover frequency than that with $\mathrm{CuN}_{4}$ moieties. It was well known that the addition of one $\mathrm{N}$ coordinated to the axial direction of $\mathrm{MN}_{4}$ would result in a higher activity. Our result revealed that decreasing the $\mathrm{N}$ coordination number of active center could also lead to a greatly enhanced activity, which provides significant inspiration on design and preparing high-performance single atom catalysts.

\section{Experimental Section}

Preparation of $\mathbf{C u}$ SAs/NC materials. $100 \mathrm{mg}$ ZIF-8 was dispersed in $10 \mathrm{ml}$-hexane under ultrasound at room temperature until homogeneous solution was formed. Then, $50 \mu 1$ of 100 $\mathrm{mg} \mathrm{ml}{ }^{-1} \mathrm{Cu}\left(\mathrm{NO}_{3}\right)_{2}$ aqueous solution was added into the mixed solution slowly under ultrasound at room temperature. Next, the mixed solution was under stirring for $6 \mathrm{~h}$ at room temperature, centrifuged and dried in vacuum at $80{ }^{\circ} \mathrm{C}$. Then, the obtained powder was ground and calcined at $800{ }^{\circ} \mathrm{C}$ and $900{ }^{\circ} \mathrm{C}$ for $1 \mathrm{~h}$ in argon atmosphere, labelled as $\mathrm{Cu}$ 
SAs/NC-800 and $\mathrm{Cu}$ SAs/NC-900, respectively. The commercial Pt/C catalyst and the pyrolyzed ZIF-8 (calcined at $800{ }^{\circ} \mathrm{C}$ and $900{ }^{\circ} \mathrm{C}$ for $1 \mathrm{~h}$ in argon atmosphere, labelled as NC800 and NC-900, respectively) were used as references.

Details for Characterizations, Electrochemical tests and DFT calculation are presented in the Supporting Information.

\section{Supporting Information}

Supporting Information is available from the Wiley Online Library or from the author.

\section{Acknowledgements}

This work was supported by the National Natural Science Foundation of China (51873174 and 21902150) and China Industrial Innovation of Key Research and Development Project of Shaanxi Province (No. 2019ZDLGY16-09). We thank the photoemission endstations beamline 1W1B station in the Beijing Synchrotron Radiation Facility (BSRF), BL14W1 at the Shanghai Synchrotron Radiation Facility and BL10B and BL11U at the National Synchrotron Radiation Laboratory for help with the characterizations.

Received:

Revised:

Published online:

\section{References}

[1] R. Paul, F. Du, L. Dai, Y. Ding, Z. L. Wang, F. Wei, A. Roy, Adv. Mater. 2019, 31, 1970094. J. Diao, Y. Qiu, S. Liu, W. Wang, K. Chen, H. Li, W. Yuan, Y. Qu, X. Guo, Adv.

Mater. 2019, 1905679.

[3] J. Li, M. Chen, D.A. Cullen, S. Hwang, M. Wang, B. Li, K. Liu, S. Karakalos, M. Lucero, H. Zhang, C. Lei, H. Xu, G.E. Sterbinsky, Z. Feng, D. Su, K.L. More, G. Wang, Z. Wang, G. Wu, Nat. Catal. 2018, 1, 935.

[4] R. Cao, R. Thapa, H. Kim, X. Xu, M. Gyu Kim, Q. Li, N. Park, M. Liu, J. Cho, Nat. Commun. 2013, 4, 2076.

[5] M.K. Debe, Nature 2012, 486, 43.

[6] R. Cao, J.-S. Lee, M. Liu, J. Cho, Adv. Ener. Mater. 2012, 2, 816. 
[7] Y. Qu, L. Wang, Z. Li, P. Li, Q. Zhang, Y. Lin, F. Zhou, H. Wang, Z. Yang, Y. Hu, M. Zhu, X. Zhao, X. Han, C. Wang, Q. Xu, L. Gu, J. Luo, L. Zheng, Y. Wu, Adv. Mater. 2019, $31,1904496$.

[8] C. Zhu, S. Fu, Q. Shi, D. Du, Y. Lin, Angew. Chem. Int. Ed. 2017, 56, 13944.

[9] J. Wang, G. Han, L. Wang, L. Du, G. Chen, Y. Gao, Y. Ma, C. Du, X. Cheng, P. Zuo, G. Yin, Small 2018, 14, 1704282.

[10] Y. Chen, S. Ji, Y. Wang, J. Dong, W. Chen, Z. Li, R. Shen, L. Zheng, Z. Zhuang, D. Wang, Y. Li, Angew. Chem. Int. Ed. 2017, 56, 6937

[11] P. Yin, T. Yao, Y. Wu, L. Zheng, Y. Lin, W. Liu, H. Ju, J. Zhu, X. Hong, Z. Deng, G. Zhou, S. Wei, Y. Li, Angew. Chem. Int. Ed. 2016, 55, 10800.

[12] Y. He, S. Hwang, D.A. Cullen, M.A. Uddin, L. Langhorst, B. Li, S. Karakalos, A.J. Kropf, E.C. Wegener, J. Sokolowski, M. Chen, D. Myers, D. Su, K.L. More, G. Wang, S. Litster, G. Wu, Energy Environ. Sci. 2019, 12, 250.

[13] Z. Zhang, J. Sun, F. Wang, L. Dai, Angew. Chem. Int. Ed. 2018, 57, 9038.

[14] L. Jiao, G. Wan, R. Zhang, H. Zhou, S.-H. Yu, H.-L. Jiang, Angew. Chem. Int. Ed. 2018, 57,8525 .

[15] Y. Han, Y.-G. Wang, W. Chen, R. Xu, L. Zheng, J. Zhang, J. Luo, R.-A. Shen, Y. Zhu, W.-C. Cheong, C. Chen, Q. Peng, D. Wang, Y. Li, J. Am. Chem. Soc. 2017, 139, 17269.

[16] A. Zitolo, V. Goellner, V. Armel, M.T. Sougrati, T. Mineva, L. Stievano, E. Fonda, F. Jaouen, Nat. Mater. 2015, 14, 937.

[17] W. Liu, L. Zhang, X. Liu, X. Liu, X. Yang, S. Miao, W. Wang, A. Wang, T. Zhang, J. Am. Chem. Soc. 2017, 139, 10790.

[18] Y.-N. Gong, L. Jiao, Y. Qian, C.-Y. Pan, L. Zheng, X. Cai, B. Liu, S.-H. Yu, H.-L. Jiang, Angew. Chem. Int. Ed. 2020, 59, 2705.

[19] H. Shen, E. Gracia-Espino, J. Ma, H. Tang, X. Mamat, T. Wagberg, G. Hu, S. Guo, Nano Energy 2017, 35, 9. 
[20] D. A. Proshlyakov, M. A. Pressler, G. T. Babcock, Proc. Natl. Acad. Sci. U. S. A. 1998, 95, 8020.

[21] N. Makino, P. Mcmahill, H. S. Mason, T. H. Moss, J. Biol. Chem. 1974, 249, 6062.

[22] Z. Yang, B. Chen, W. Chen, Y. Qu, F. Zhou, C. Zhao, Q. Xu, Q. Zhang, X. Duan, Y. Wu, Nat. Commun. 2019, 10, 3734.

[23] Y. Qu, Z. Li, W. Chen, Y. Lin, T. Yuan, Z. Yang, C. Zhao, J. Wang, C. Zhao, X. Wang, G. Zhou, Z. Zhuang, Y. Wu, Y. Li, Nat. Catal. 2018, 1, 781.

[24] F. Li, G.-F. Han, H.-J. Noh, S.-J. Kim, Y. Lu, H.Y. Jeong, Z. Fu, J.-B. Baek, Energy Environ. Sci. 2018, 11, 2263.

[25] Z. Jiang, W. Sun, H. Shang, W. Chen, T. Sun, H. Li, J. Dong, J. Zhou, Z. Li, Y. Wang, R. Cao, R. Sarangi, Z. Yang, D. Wang, J. Zhang, Y. Li, Energy Environ. Sci. 2019, 12, 3508. [26] L. Cui, L. Cui, Z. Li, J. Zhang, H. Wang, S. Lu, Y. Xiang, J. Mater. Chem. A 2019, 7, 16690.

[27] H. Wu, H. Li, X. Zhao, Q. Liu, J. Wang, J. Xiao, S. Xie, R. Si, F. Yang, S. Miao, X. Guo, G. Wang, X. Bao, Energy Environ. Sci. 2016, 9, 3736.

[28] C. Zhao, X. Dai, T. Yao, W. Chen, X. Wang, J. Wang, J. Yang, S. Wei, Y. Wu, Y. Li, J. Am. Chem. Soc. 2017, 139, 8078.

[29] C. Zhao, C. Xiong, X. Liu, M. Qiao, Z. Li, T. Yuan, J. Wang, Y. Qu, X. Wang, F. Zhou, Q. Xu, S. Wang, M. Chen, W. Wang, Y. Li, T. Yao, Y. Wu, Y. Li, Chem. Commun. 2019, 55, 2285.

[30] S. Z. Liu, M. G. White, P. Liu, J. Phys. Chem. C 2016, 120, 15288. 

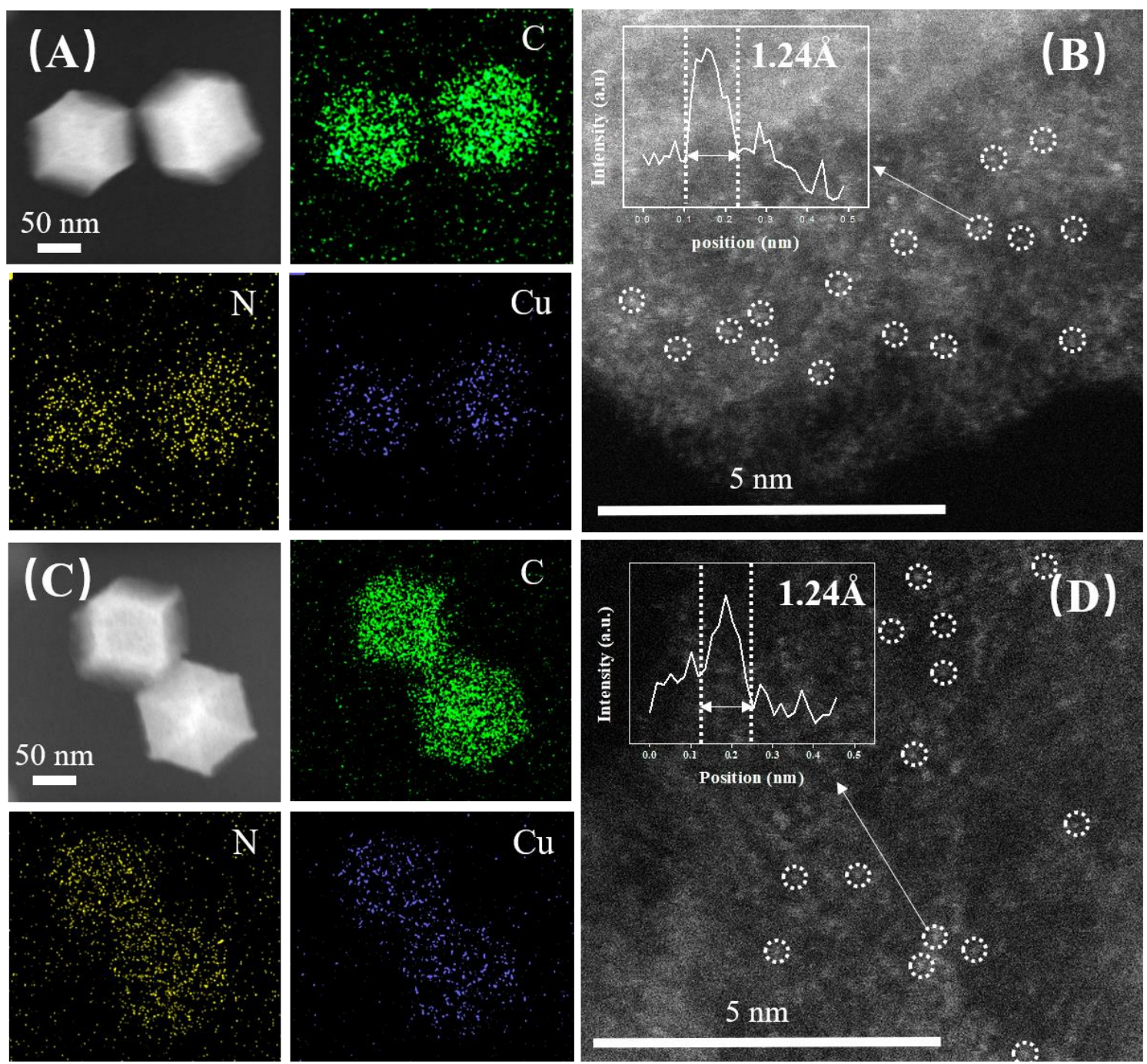

Figure 1. Characterization of Cu SAs/NC. HAADF-TEM imaging of Cu SAs/NC-800 (A) and $\mathrm{Cu}$ SAs/NC-900 (C) coupled with electron energy loss spectroscopy; HAADF-STEM image of $\mathrm{Cu}$ SAs/NC-800 (B) and $\mathrm{Cu}$ SAs/NC-900 (D), the inset showed corresponding intensity profiles. 

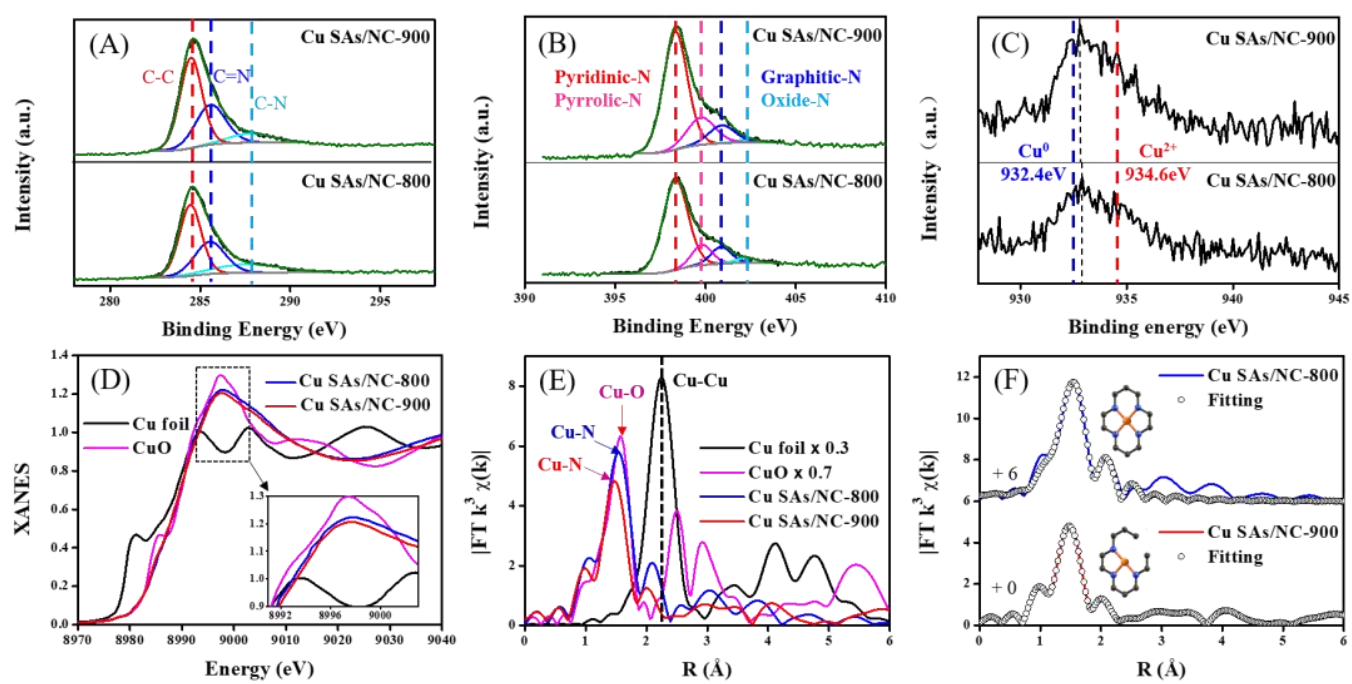

(G)
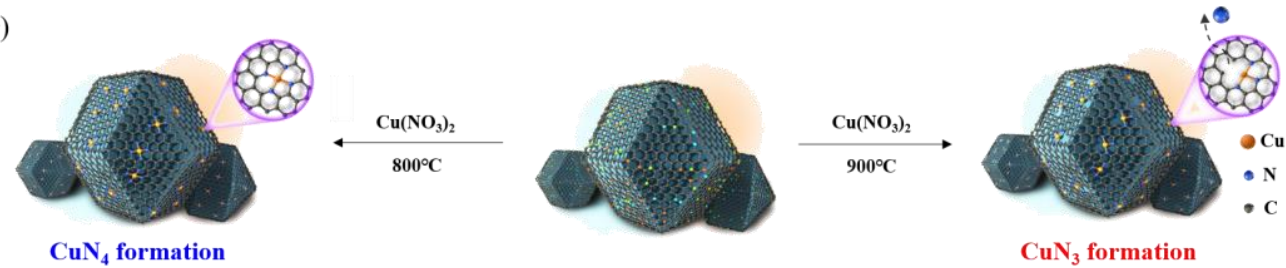

Figure 2. Chemical state, coordination information and preparation mechanism of $\mathrm{Cu}$ SAs/NC. C 1s (A), N 1s (B) and Cu 2p (C) XPS spectra of Cu SAs/NC-800 and Cu SAs/NC900; (D) $\mathrm{Cu} \mathrm{K}$ edge XANES spectra of $\mathrm{Cu}$ SAs/NC and the reference samples; (E) $\mathrm{K}^{3}$ weighted $\chi(\mathrm{k})$ function of EXAFS spectra for $\mathrm{Cu}$ SAs/NC and the reference samples. the $\mathrm{Cu}$ foil and $\mathrm{CuO}$ data were transformed by 0.3 and 0.7, respectively; (F) EXAFS fitting curve for $\mathrm{Cu}$ SAs/NC-800 and $\mathrm{Cu}$ SAs/NC-900, respectively. Inset showed the proposed $\mathrm{CuN}_{3}$ and $\mathrm{CuN}_{4}$ coordination environment, respectively; (G) Supposed formation mechanism of $\mathrm{CuN}_{3}$ and $\mathrm{CuN}_{4}$. 

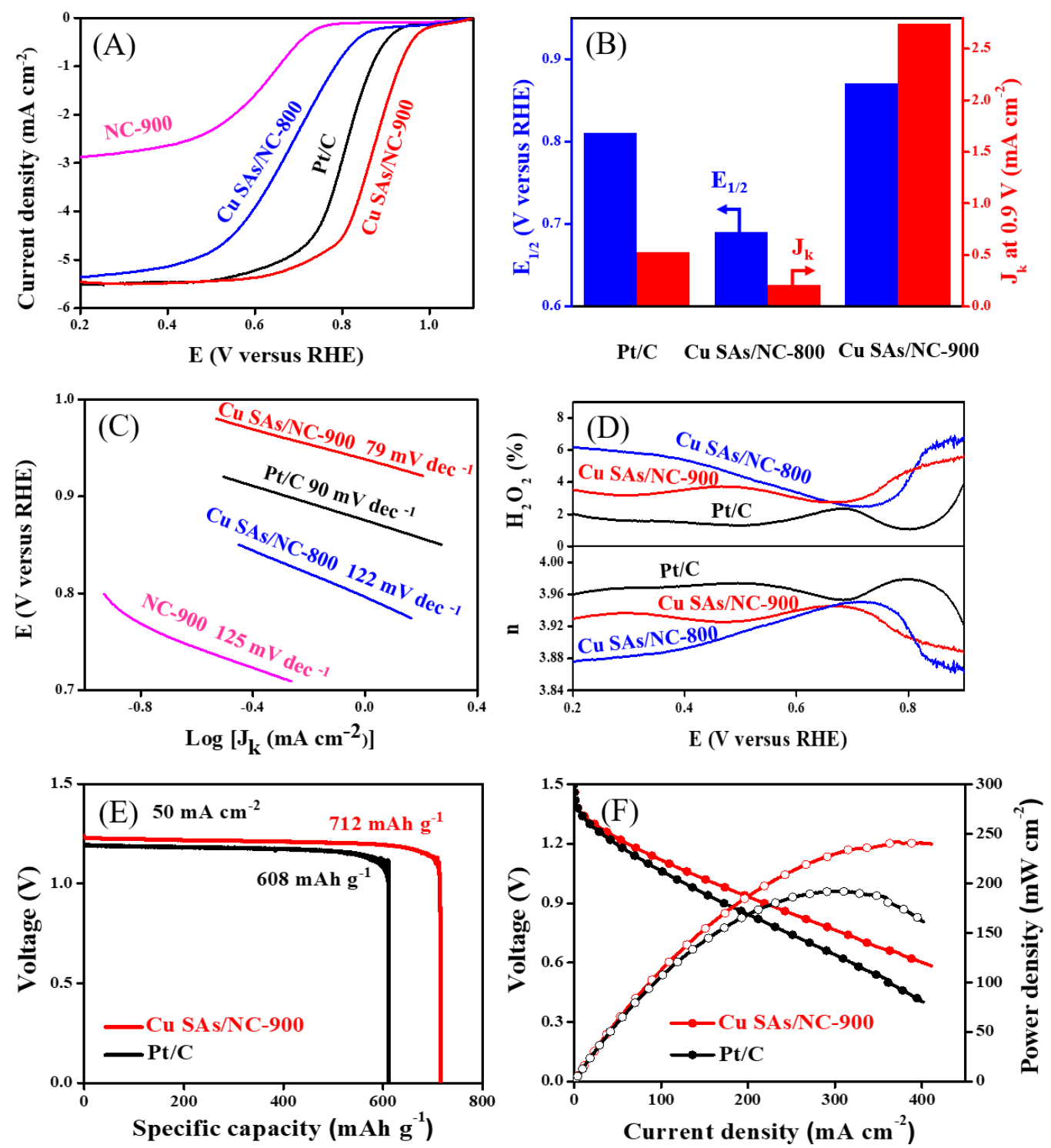

Figure 3. Electrochemical evaluation of $\mathrm{Cu}$ SAs/NC. (A) Polarization curve for $\mathrm{Cu}$ SAs/NC-800, Cu SAs/NC-900 and the reference samples; (B) Half-wave potentials $\left(\mathrm{E}_{1 / 2}\right)$ and kinetic currents $\left(\mathrm{J}_{\mathrm{k}}\right.$, at $\left.0.9 \mathrm{~V}\right)$ of $\mathrm{Cu} \mathrm{SAs} / \mathrm{NC}$ and $\mathrm{Pt} / \mathrm{C}$; (C) Corresponding Tafel plots of various samples; (D) Electron transfer number (n, bottom) and $\mathrm{H}_{2} \mathrm{O}_{2}$ yield (top) versus potential; (E) Specific capacities of $\mathrm{Cu}$ SAs/NC-900 and Pt/C based Zn-air battery; (F) Discharge polarization and corresponding power density plots of $\mathrm{Cu}$ SAs/NC-900 and Pt/C based $\mathrm{Zn}$-air battery. 
(A)
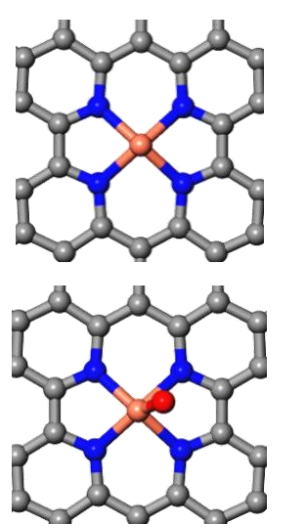

(C)
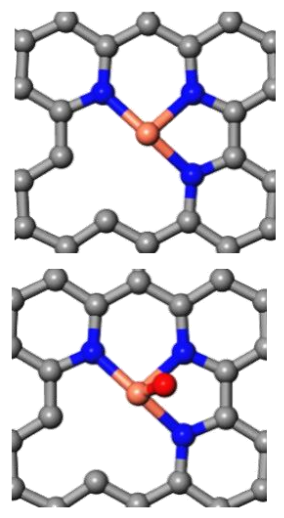
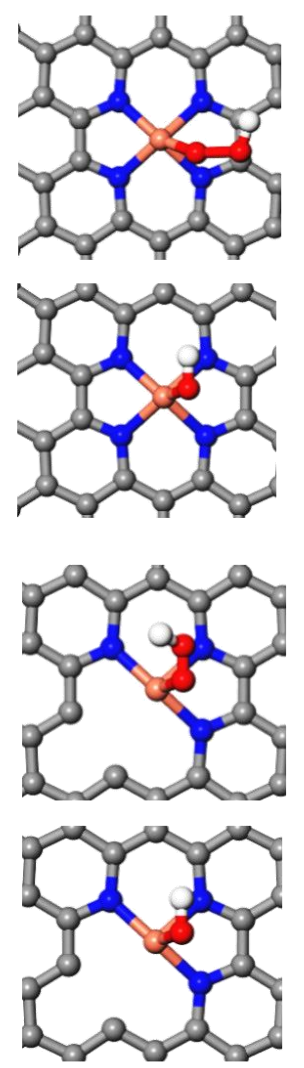

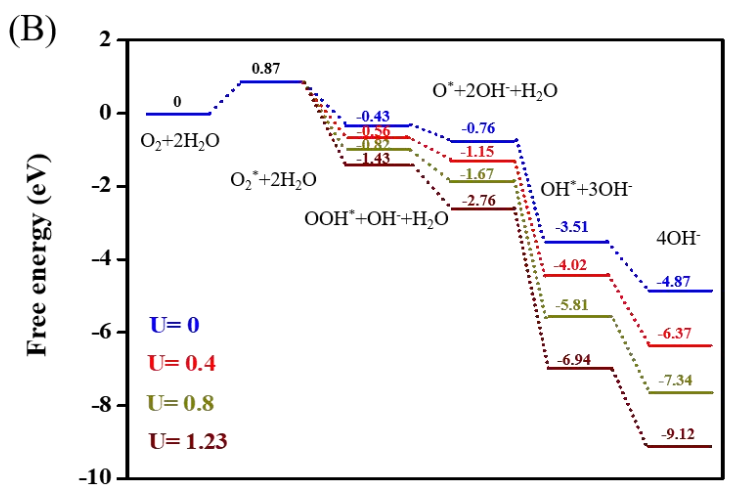

Reaction path

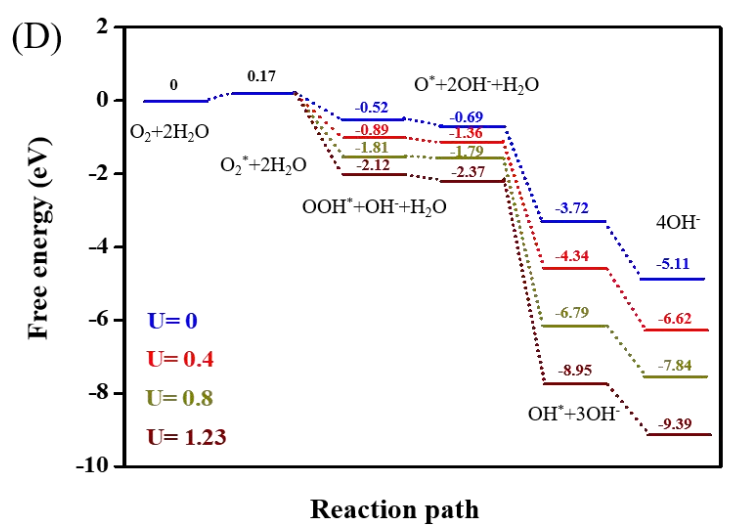

Figure 4. Theoretical study. View of the model, adsorbed $\mathrm{OOH}, \mathrm{O}$ and $\mathrm{OH}$, respectively, over the $\mathrm{CuN}_{4}$ model (A) and $\mathrm{CuN}_{3}$ model (C). Gray, blue, orange, red and white represent $\mathrm{C}$, $\mathrm{N}, \mathrm{Cu}, \mathrm{O}$ and $\mathrm{H}$ atoms, respectively. Free energy diagrams for ORR process on $\mathrm{CuN}_{4}(\mathrm{~B})$ and $\mathrm{CuN}_{3}$ (D) at different overpotentials. 
An ionic exchange strategy is developed to fabric atomically dispersed $\mathrm{Cu}-\mathrm{N}-\mathrm{C}$ material with unsaturated $\mathrm{Cu}-\mathrm{N}$ centers $\left(\mathrm{Cu}-\mathrm{N}_{3}\right.$ moieties $)$, which possess a higher half-wave potential of $180 \mathrm{mV}$ and the 10 times turnover frequency than that with $\mathrm{Cu}-\mathrm{N}_{4}$ moieties in the ORR test. Furthermore, the optimum $\mathrm{Cu}-\mathrm{N}_{3}$ catalyst demonstrates a better performance in ORR and zinc-air batteries compared with commercial Pt/C.

Keyword: single atom, copper, unsaturated coordination, oxygen reduction reaction

S. Ma, Z. Han, K. Leng, X. Liu, Y. Wang*, Y. Qu* and J. Bai*

Ionic Exchange of Metal-Organic Frameworks for Constructing Unsaturated Copper Single Atom Catalysts for Boosting Oxygen Reduction Reaction

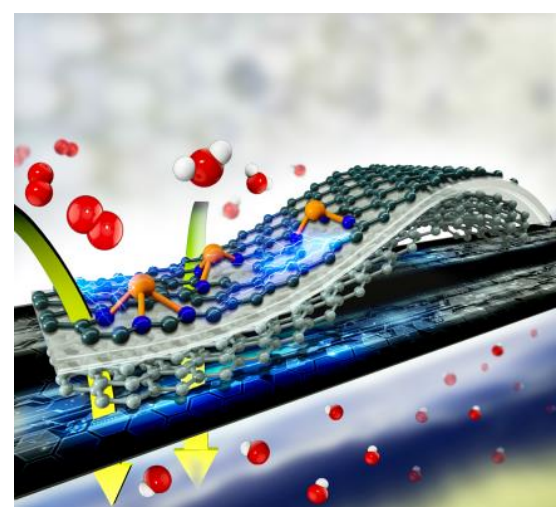


Copyright WILEY-VCH Verlag GmbH \& Co. KGaA, 69469 Weinheim, Germany, 2016.

\section{Supporting Information}

Ionic Exchange of Metal-Organic Frameworks for Constructing Unsaturated Copper Single Atom Catalysts for Boosting Oxygen Reduction Reaction

Shenghua Ma, Zheng Han, Kunyue Leng, Xiaojie Liu, Yi Wang*, Yunteng Qu* and Jinbo $B a i^{*}$

Material characterizations. X-ray diffraction patterns were performed on Bruker D8 ADVANCE diffractometer with $\mathrm{Cu} \mathrm{K} \alpha$ radiation $(\lambda=0.15418 \mathrm{~nm})$. High-resolution TEM testing was carried out using a FEI Tecnai G2 F20 S-TWIN. HAADF-STEM images and corresponding EELS were obtained on a JEOL JEMARM200F TEM/STEM system. XPS measurements were performed on a PHI-5400 photoelectron spectrometer. $\mathrm{N}_{2}$ isotherms was obtained on Micrometics ASAP 2020. Elemental analysis of copper in the solid samples was detected by ICP-OES (Optima 7300 DV). XAFS spectra at the copper K edge were collected at the Beijing Synchrotron Radiation Facility in China.

Electrochemical tests. Electrochemical measurements were carried out on an electrochemical workstation (CHI 760E) with $5 \mathrm{~mm}$ diameter glassy carbon rotating-disk electrode (RDE), $\mathrm{Ag} / \mathrm{AgCl}$ reference electrode and graphite rod counter electrode.

The catalyst ink was prepared by mixing $1 \mathrm{mg}$ catalyst with $480 \mu \mathrm{l}$ ethanol, $480 \mu \mathrm{l} \mathrm{H}_{2} \mathrm{O}$ and $40 \mu \mathrm{l} 5 \%$ Nafion solution under ultrasonic. And, the working electrode was prepared by coating $5 \mu \mathrm{l}$ catalyst ink on glassy carbon RDE for 4 times.

The TOF values were obtained based on the equation:

$\mathrm{TOF}=\frac{J \times a}{4 \times m \times F}$

where $\mathrm{J}$ represents the current density measured at $0.9 \mathrm{~V}$, a is the surface area of the glassy carbon disk electrode $\left(0.196 \mathrm{~cm}^{2}\right), 4$ is the number of electrons transferred during $\mathrm{O}_{2}$ 
reduction, $\mathrm{m}$ is the mole number of copper single sites on the electrode, and $\mathrm{F}$ is the Faraday constant $\left(96485 \mathrm{C} \mathrm{mol}^{-1}\right)$.

The RDE measurement was performed at a sweep rate of $10 \mathrm{mV} \mathrm{s}^{-1}$ with different rotating speeds (900 to 2500 r.p.m.). The electron transfer number (n) and kinetic current density $\left(\mathrm{J}_{\mathrm{K}}\right)$ were obtained according to the Koutecky-Levich equation:

$\frac{1}{J}=\frac{1}{J_{L}}+\frac{1}{J_{K}}=\frac{1}{B \omega^{\frac{1}{2}}}+\frac{1}{J_{K}}$

$\mathrm{B}=0.62 n F C_{0} D_{0}^{\frac{2}{3}} V^{-\frac{1}{6}}$

where $\mathrm{J}$ is the current density measured from the ORR, $\mathrm{J}_{\mathrm{K}}$ is the kinetic current density, $\mathrm{J}_{\mathrm{L}}$ is the limiting current density, $\omega$ represents the angular velocity of the disk, $\mathrm{C}_{0}$ is the bulk concentration of $\mathrm{O}_{2}\left(1.2 \times 10^{-6} \mathrm{~mol} \mathrm{~cm}^{-3}\right), \mathrm{D}_{0}$ is the diffusion coefficient of $\mathrm{O}_{2}$ in $0.1 \mathrm{M} \mathrm{KOH}$ $\left(1.9 \times 10^{-5} \mathrm{~cm}^{2} \mathrm{~s}^{-1}\right)$ and $\mathrm{V}$ is the kinematic viscosity of the electrolyte $\left(0.01 \mathrm{~cm}^{2} \mathrm{~s}^{-1}\right)$. The accelerated durability test of $\mathrm{Cu}$ SAs/NC-900 were performed by applying potential cycling between 1.0 and $0.6 \mathrm{~V}$ versus RHE for 5000 cycles $\left(\mathrm{O}_{2}\right.$ saturated $0.1 \mathrm{M} \mathrm{KOH}, 50 \mathrm{mV} \mathrm{s}{ }^{-1}$, room temperature).

The rotating ring-disk electrode (RRDE) test was carried out using high potential (1.2 V vs RHE) on the ring electrode, and the disk electrode was scanned negative $\left(10 \mathrm{mV} \mathrm{s}^{-1}\right)$. The hydrogen peroxide yield $\left(\mathrm{H}_{2} \mathrm{O}_{2}(\%)\right)$ and electron transfer number (n) was calculated based on the following equations:

$\mathrm{H}_{2} \mathrm{O}_{2}(\%)=200 \times \frac{\frac{\mathrm{I}_{\mathrm{r}}}{\mathrm{N}}}{\mathrm{I}_{\mathrm{d}}+\frac{\mathrm{I}_{\mathrm{r}}}{\mathrm{N}}}$

$\mathrm{n}=4 \times \frac{\mathrm{I}_{\mathrm{d}}}{\mathrm{I}_{\mathrm{d}}+\frac{\mathrm{I}_{\mathrm{r}}}{\mathrm{N}}}$ 
where $I_{d}$ is the disk current, $I_{r}$ is the ring current and $N=0.4$ is the current collection efficiency of the platinum ring.

The Zn-air battery was assembled in a two-electrode configuration. The air cathode was prepared by dispersing the as-prepared catalyst ink onto teflon-coated carbon fiber paper (1.0 $\mathrm{mg} \mathrm{cm}{ }^{-2}$ ), and drying at $60{ }^{\circ} \mathrm{C}$ for $2 \mathrm{~h}$. The polished $1 \mathrm{~cm}^{2}$ commercial $\mathrm{Zn}$ foil with a thickness of $0.2 \mathrm{~mm}$ was used as anode. The electrolyte was composed of $6 \mathrm{M} \mathrm{KOH}$ and saturated with $\mathrm{O}_{2}$. The battery performance was test on the as-constructed cell at room temperature with $\mathrm{CHI}$ 760 E electrochemical workstation.

DFT calculation. The calculation was carried out by first-principles base on density functional theory (DFT) with the Vienna ab initio package (VASP), and the pseudopotential by the projector-augmented wave (PAW) and the Perdew-Burke-Ernzerhof (PBE) has been used. In our work, the cut-off energy has been set to $400 \mathrm{eV}$ and the Brillouin zone has been used with a $3 \times 3 \times 1 \Gamma$-centered k-mesh for surface structure.
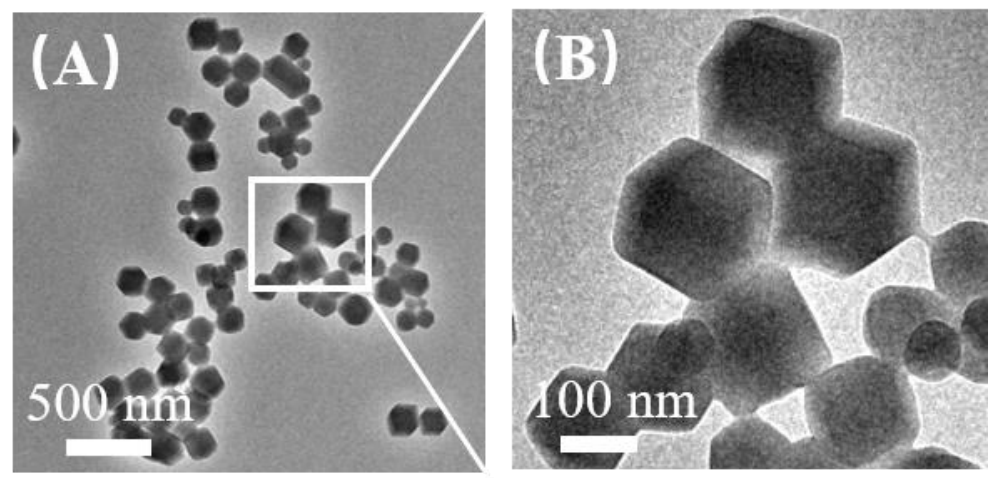

Figure S1. TEM images of ZIF-8. 

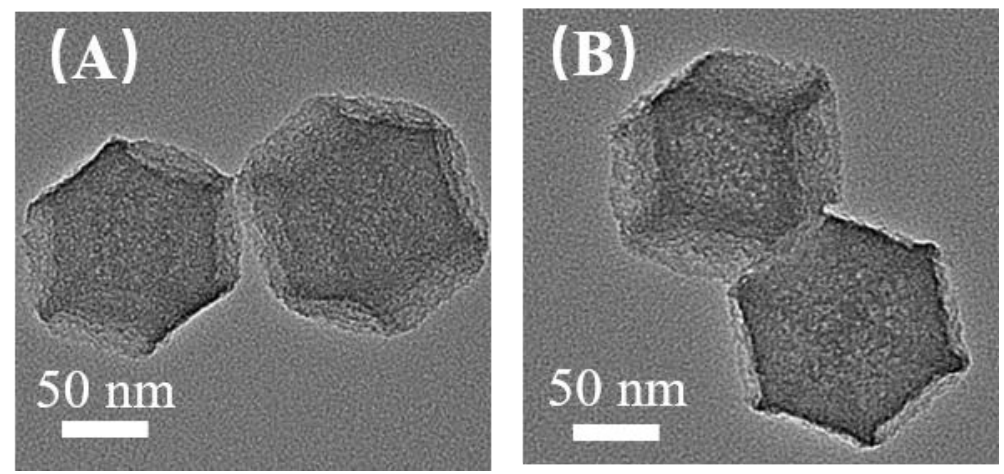

Figure S2. TEM images of $\mathrm{Cu}$ SAs/NC-800 (A) and Cu SAs/NC-900 (B).
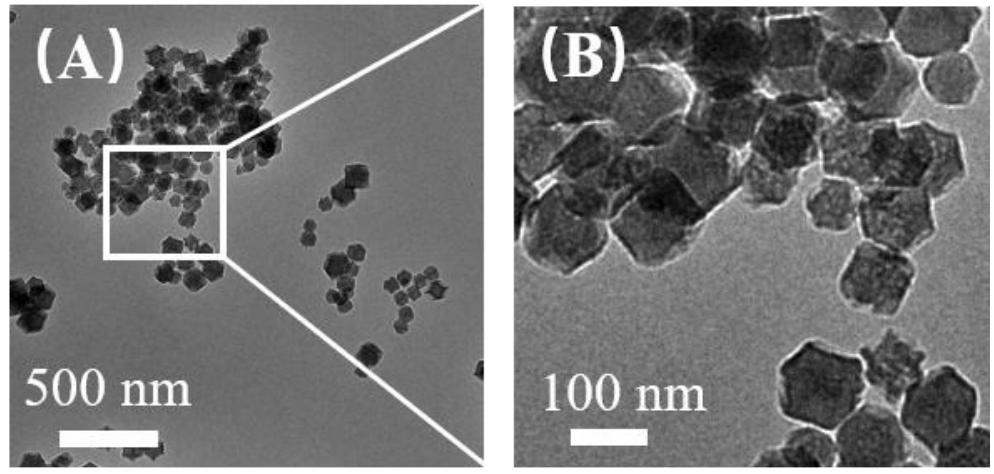

Figure S3. TEM images of NC-900.

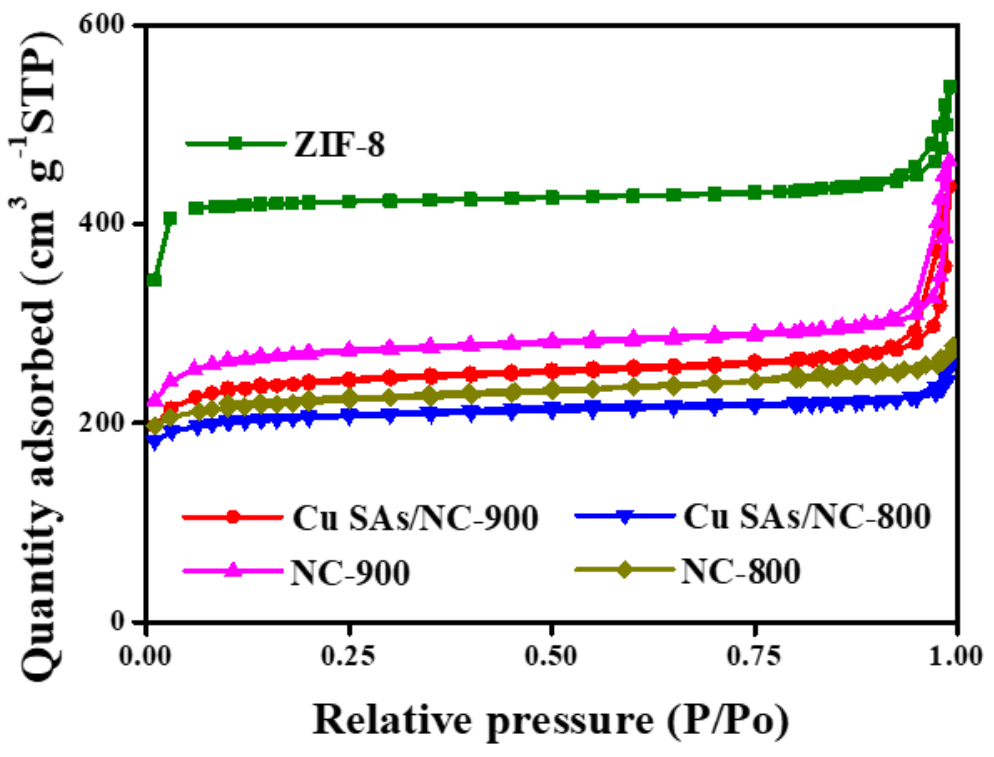

Figure $\mathbf{S 4}$. The $\mathrm{N}_{2}$ isotherms of various samples. 

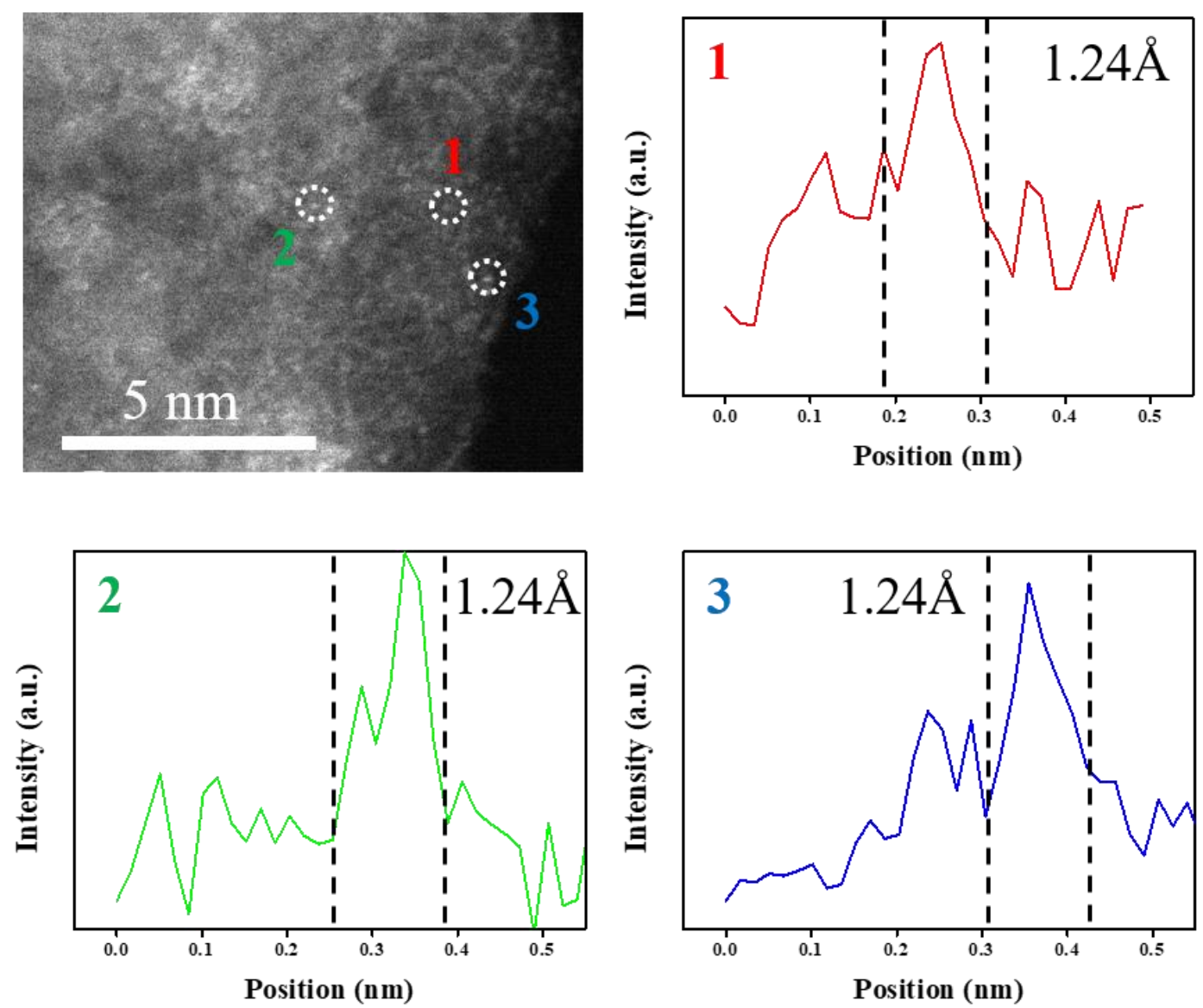

Figure S5. HAADF-STEM image of $\mathrm{Cu}$ SAs/NC-800 and the corresponding intensity profiles. 

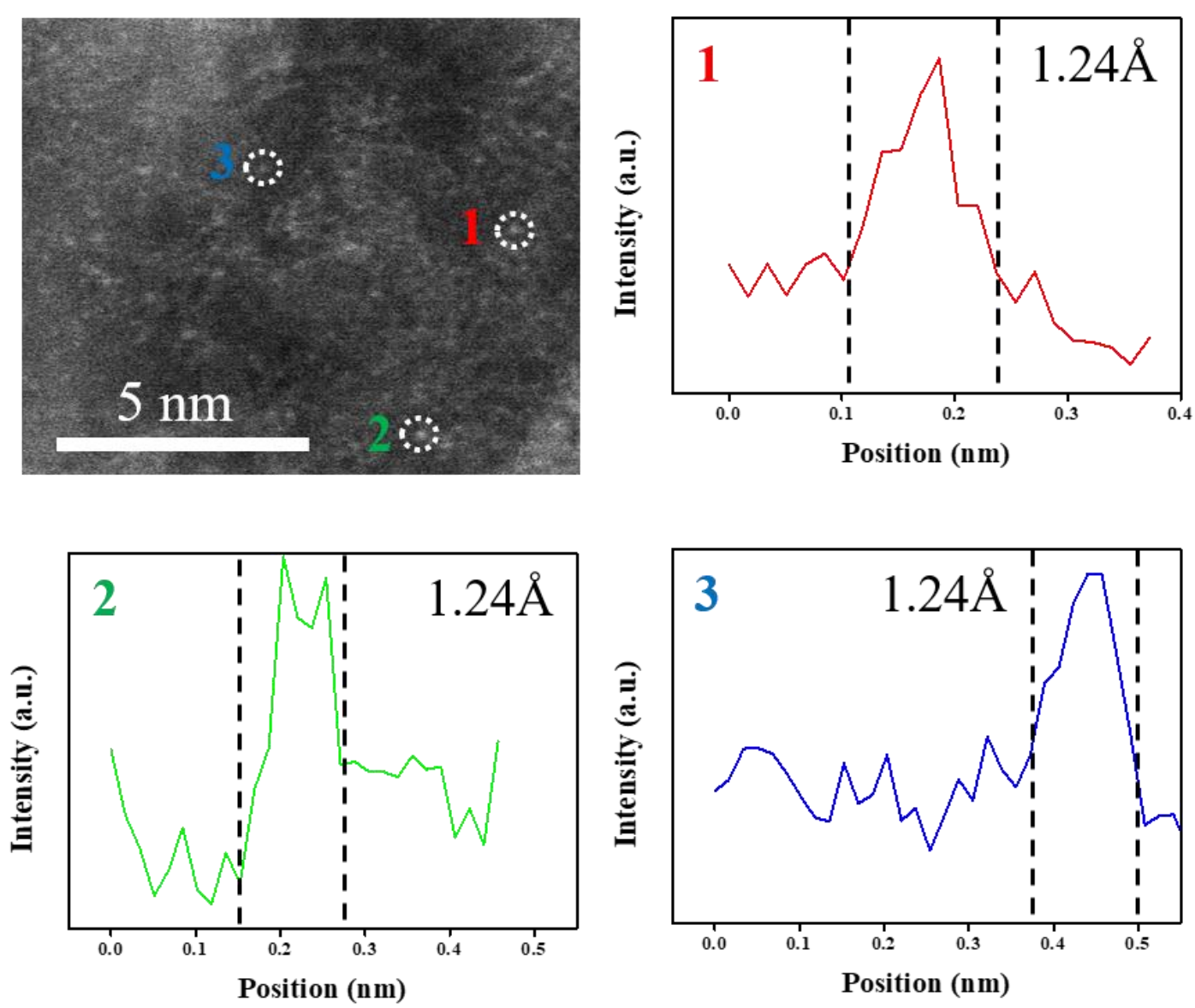

Figure S6. HAADF-STEM image of $\mathrm{Cu}$ SAs/NC-900 and the corresponding intensity profiles.

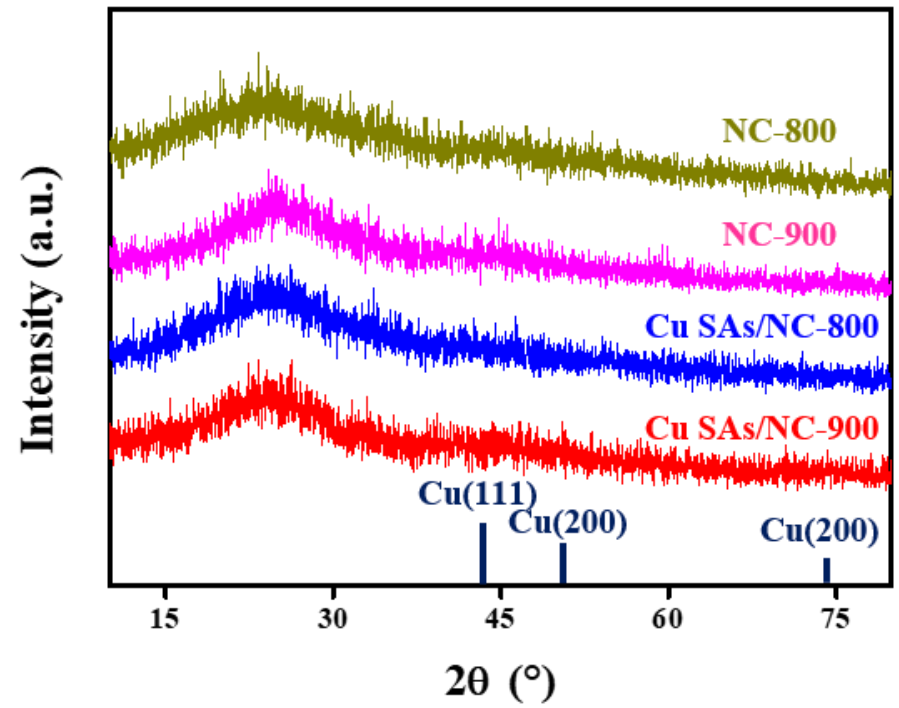

Figure S7. XRD patterns of various samples. Inset showed the position of face centered cubic Cu PDF\#04-0836. 

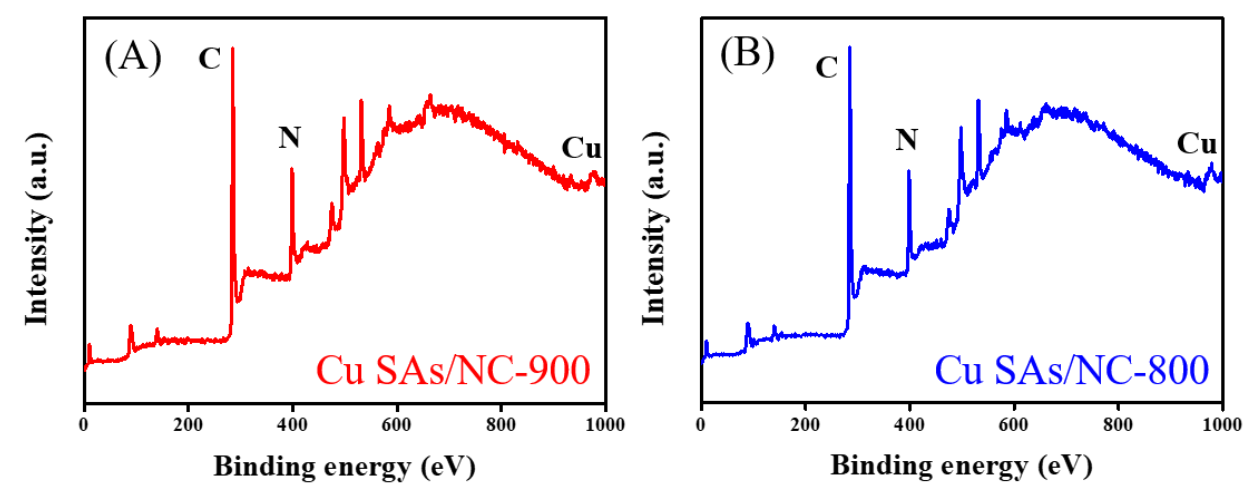

Figure S8. XPS spectra for the survey scan of Cu SAs/NC-900 (A) and Cu SAs/NC-800 (B).

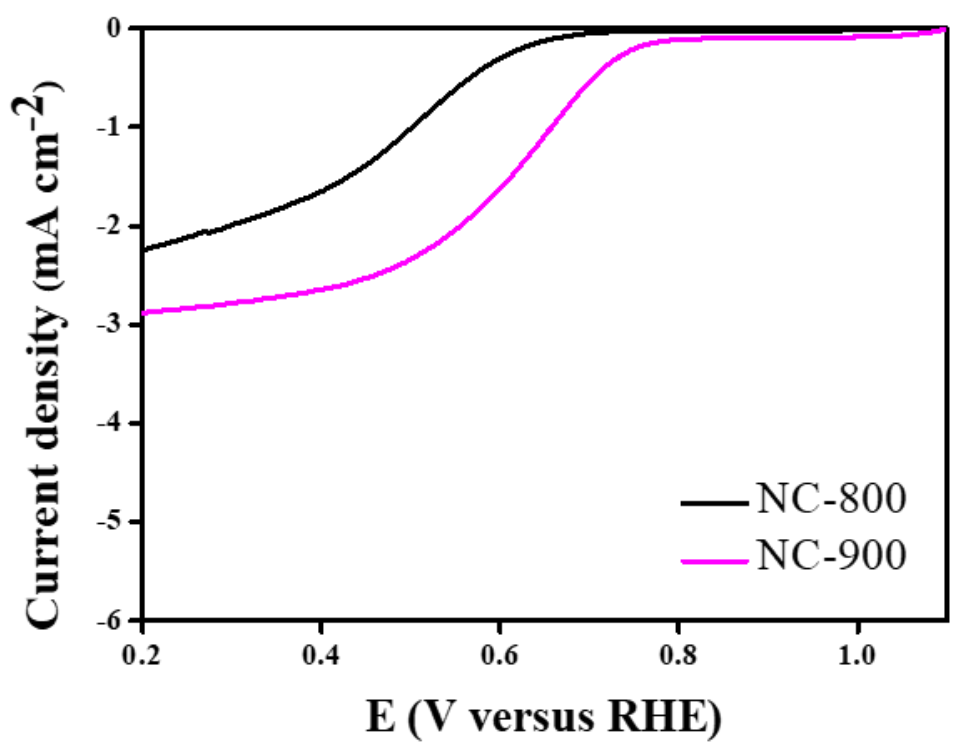

Figure S9. Polarization curve of NC-800 and NC-900.

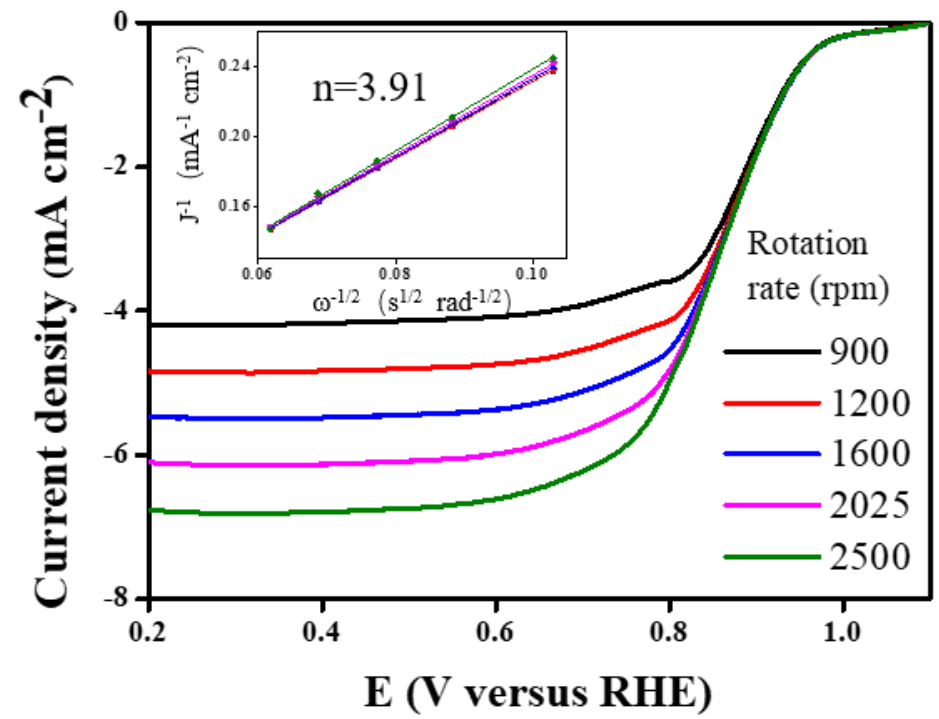


Figure S10. Polarization curves of $\mathrm{Cu}$ SAs/NC-900 at different rotation rates. Inset: Koutecky-Levich plots and the obtained electron transfer number.

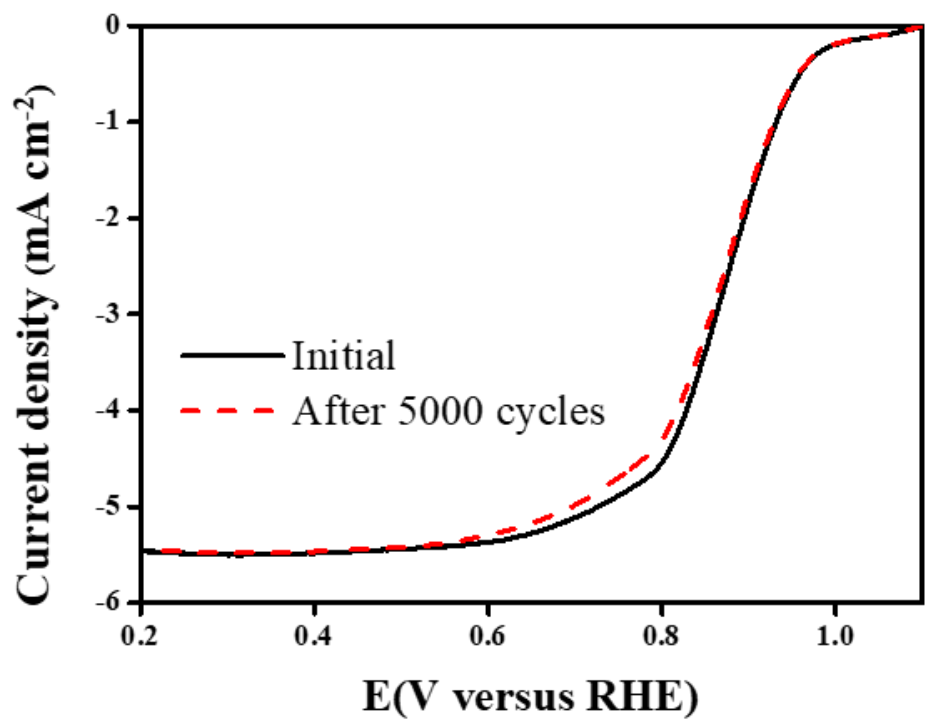

Figure S11. Polarization curves of $\mathrm{Cu}$ SAs/NC-900 before and after 5000 cycles of accelerated durability test.

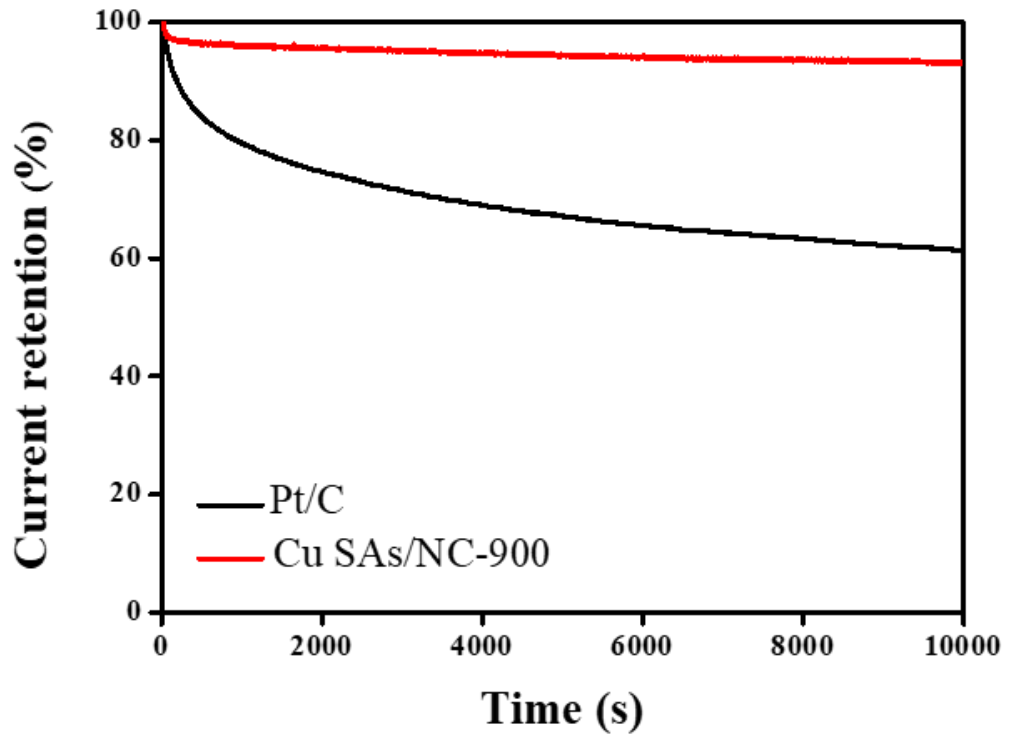

Figure S12. Chronoamperometric response of $\mathrm{Cu}$ SAs/NC-900 and $\mathrm{Pt} / \mathrm{C}$ in $0.1 \mathrm{M} \mathrm{KOH}$ solution (oxygen saturated) at $0.65 \mathrm{~V}$. 

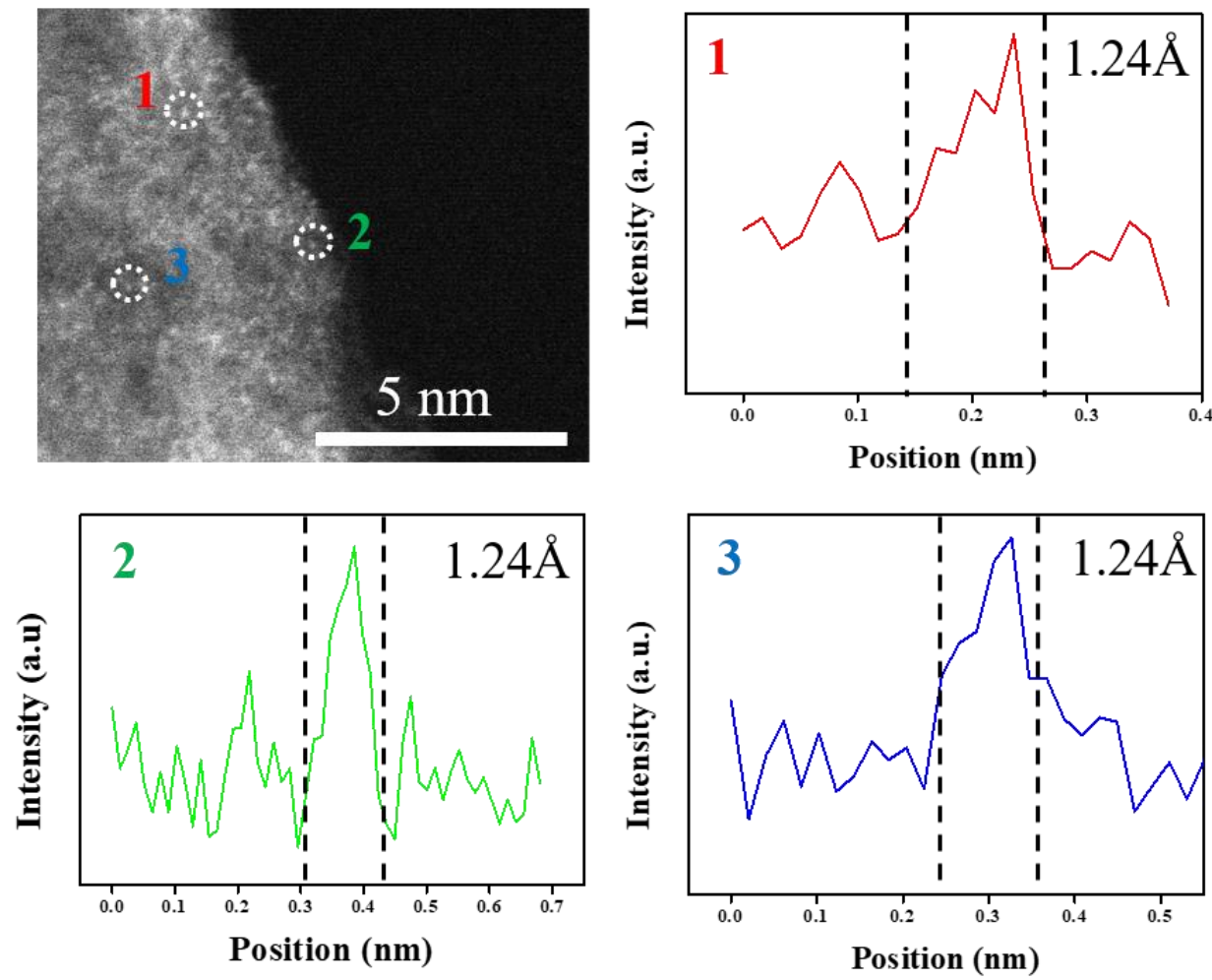

Figure S13. HAADF-STEM image of $\mathrm{Cu}$ SAs/NC-900 after durability test and the corresponding intensity profiles.

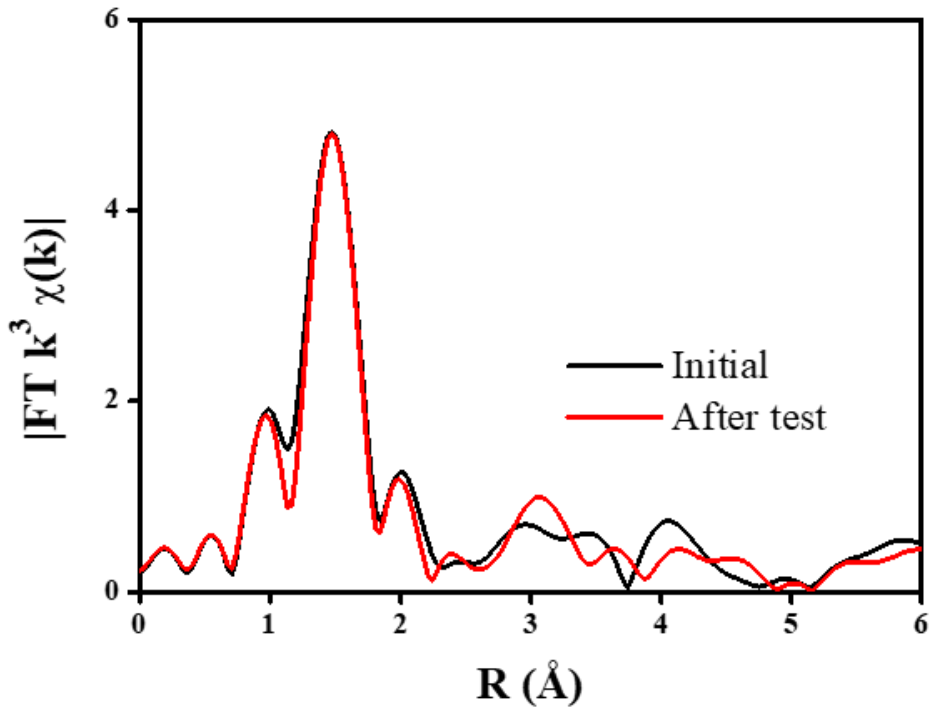

Figure S14. $\mathrm{K}^{3}$-weighted $\chi(\mathrm{k})$ function of the EXAFS spectra of $\mathrm{Cu}$ SAs/NC-900 before and after durability test. 
Table S1. Textual properties and chemical composition.

\begin{tabular}{lll}
\hline Sample & $\mathrm{Cu}(\mathrm{wt} \%)^{\mathrm{a})}$ & BET surface area $\left(\mathrm{m}^{2} \mathrm{~g}^{-1}\right)^{\mathrm{b})}$ \\
\hline ZIF-8 & - & 1184 \\
NC-800 & - & 697 \\
NC-900 & - & 774 \\
Cu SAs/NC-800 & 2.1 & 673 \\
Cu SAs/NC-900 & 1.9 & 733 \\
\hline
\end{tabular}

a) ICP-OES; ${ }^{\text {b) }}$ Brunauer-Emmett-Teller

Table S2. Structural parameters extracted from the $\mathrm{Cu}$ K-edge EXAFS fitting.

\begin{tabular}{lllllll}
\hline Sample & Scattering pair & $\mathrm{CN}$ & $\mathrm{R}[\AA]$ & $\sigma^{2}\left[\AA^{2}\right]$ & $\Delta \mathrm{E}_{0}[\mathrm{eV}]$ & $\mathrm{R}$ factor \\
\hline $\mathrm{Cu} \mathrm{SAs} / \mathrm{NC}-800$ & $\mathrm{Cu}-\mathrm{N} / \mathrm{C}$ & 4.1 & 1.98 & 0.00419 & -4.36814 & 0.00803 \\
$\mathrm{Cu} \mathrm{SAs} / \mathrm{NC}-900$ & $\mathrm{Cu}-\mathrm{N} / \mathrm{C}$ & 3.0 & 1.96 & 0.00308 & -3.88223 & 0.00864 \\
\hline
\end{tabular}

$\mathrm{CN}$, coordination number; $\mathrm{R}$, interatomic distance; $\sigma 2$, Debye-Waller factor; $\Delta \mathrm{E} 0$, edge-energy shift; $\mathrm{R}$ factor is used to value the goodness of the fitting.

Table S3. Comparison of the ORR activity between $\mathrm{Cu}$ SAs/NC-900 and other noble metal free catalysts under alkaline condition $(0.1 \mathrm{M} \mathrm{KOH})$ in literature.

\begin{tabular}{|c|c|c|c|c|}
\hline Sample & $\mathrm{E}_{1 / 2}(\mathrm{~V}$ vs RHE) & TOF $(\mathrm{Hz})$ & $\mathrm{n}$ & Reference \\
\hline $\mathrm{Cu}$ SAs/NC-900 & 0.87 & 0.16 & 3.91 & This work \\
\hline $\mathrm{FeN}_{\mathrm{x}} / \mathrm{C}$ & 0.82 & - & - & J. Am. Chem. Soc. 2014, 136, 10882. \\
\hline $\mathrm{W}_{2} \mathrm{~N} / \mathrm{WC}$ & 0.83 & & 3.92 & Adv. Mater. 2019, 1905679. \\
\hline Fe single atoms & 0.92 & 0.16 & 3.8 & Small 2018, 14, 1704282. \\
\hline $\mathrm{Fe}-\mathrm{N} / \mathrm{C}-800$ & 0.81 & & 3.96 & J. Am. Chem. Soc. 2014, 136, 11027. \\
\hline$(\mathrm{Fe}-\mathrm{P})_{\mathrm{n}} \mathrm{MOF}$ & 0.81 & 0.1 & 3.82 & J. Am. Chem. Soc. 2012, 134, 6707. \\
\hline $\mathrm{Co}-\mathrm{N} / \mathrm{CNFs}$ & 0.82 & & 3.4 & ACS. Catal. 2017, 7, 6864. \\
\hline CoZn-NC-700 & 0.82 & & 3.67 & ACS Appl. Mater. Interfaces. 2017, 9, 12574. \\
\hline pCNT@Fe $1.5 @ \mathrm{GL}$ & 0.81 & 0.24 & 3.96 & Adv. Mater. 2017, 29, 1606534. \\
\hline Co SAs/N-C(900) & 0.88 & 0.14 & 3.98 & Angew. Chem. Int. Ed. 2016, 55, 10800. \\
\hline NC@Co-NGC & 0.82 & & 3.9 & Adv. Mater. 2017, 27, 1700874. \\
\hline $\mathrm{Fe} \mathrm{SAs} / \mathrm{N}-\mathrm{C}$ & 0.9 & 0.1 & 3.9 & Angew. Chem. Int. Ed. 2017, 56, 6937. \\
\hline CoP-CMP & 0.81 & & 3.94 & Adv. Mater. 2014, 26, 1450. \\
\hline $\mathrm{Cu}-\mathrm{N}-\mathrm{C}$ & 0.869 & & 3.97 & Energy Environ. Sci. 2018, 11, 2263. \\
\hline $\mathrm{Cu}-\mathrm{N} @ \mathrm{C}$ & 0.8 & & 3.96 & Energy Environ. Sci. 2016, 9, 3736. \\
\hline $\mathrm{Cu}$ ISAS/NC & 0.92 & & 3.99 & Nat. Commun. 2019, 10, 3734. \\
\hline $\mathrm{CoO}_{\mathrm{x}} \mathrm{NPs} / \mathrm{BNG}$ & 0.805 & & 4.0 & Angew. Chem. Int. Ed. 2017, 56, 7121. \\
\hline $\mathrm{FeN}_{4}-\mathrm{GN}$ & 0.86 & & 3.99 & Nano Energy 2017, 32, 353. \\
\hline LDH@ZIF-67-800 & 0.83 & & 4.0 & Adv. Mater. 2016,28, 2337. \\
\hline NCNTFs & 0.87 & & 3.97 & Nature Energy 2016, 1, 15006. \\
\hline $\mathrm{Cu}-\mathrm{SA} / \mathrm{SNC}$ & 0.893 & & 4.0 & Energy Environ. Sci. 2019, 12, 3508 \\
\hline
\end{tabular}


Table S4. Comparison of the peak power density of $\mathrm{Cu}$ SAs/NC-900 based Zn-air battery and other reported $\mathrm{Zn}$-air batteries in literature.

\begin{tabular}{|c|c|c|c|}
\hline Sample & Loading $\left(\mathrm{mg} \mathrm{cm}^{-2}\right)$ & $\begin{array}{l}\text { Peak power density }(\mathrm{mW} \\
\left.\mathrm{cm}^{-2}\right)\end{array}$ & Reference \\
\hline Cu SAs/NC-900 & 1 & 242 & This work \\
\hline Cu-N@C & 0.4 & 210 & Energy Environ. Sci. 2016, 9, 3736. \\
\hline $\mathrm{W}_{2} \mathrm{~N} / \mathrm{WC}$ & 0.6 & 172 & Adv. Mater. 2019, 1905679. \\
\hline Fe@N-C-700 & 2.2 & 220 & Nano Energy 2015, 13, 387. \\
\hline $\mathrm{Mn}_{3} \mathrm{O}_{4} /$ graphene & 2 & 120 & Energy Environ. Sci. 2011, 4, 4148. \\
\hline $\mathrm{Fe}$ SAs/N-G & 1 & 275 & Adv. Mater. 2019, 1904496. \\
\hline CuPt-NC & 2 & 251 & ACS Catal. 2015, 5, 1445. \\
\hline $\mathrm{Fe}-\mathrm{N}-\mathrm{MC}$ & 1.2 & 190 & Nano Energy 2016, 26, 131. \\
\hline Co-doped $\mathrm{TiO}_{2}$ & 2 & 136 & J. Mater. Chem. A 2016, 4, 7841. \\
\hline $\mathrm{Co}_{3} \mathrm{O}_{4}-\mathrm{SP} / \mathrm{NGr}$ & 1 & 190 & $\begin{array}{l}\text { ACS Appl. Mater. Interfaces 2015, 7, } \\
21138 .\end{array}$ \\
\hline $\mathrm{Cu}$ ISAS/NC & 1 & 280 & Nat. Commun. 2019, 10, 3734. \\
\hline $\mathrm{N}-\mathrm{CNT}$ & 0.2 & 70 & Electrochim. Acta 2011, 56, 5080. \\
\hline $\mathrm{Co}_{4} \mathrm{~N} / \mathrm{CNW} / \mathrm{CC}$ & 1 & 174 & J. Am. Chem. Soc. 2016, 138, 10226. \\
\hline $\mathrm{FeCo}-\mathrm{N}-\mathrm{C}$ & 1.5 & 232 & J. Power Sources 2011, 196, 3673. \\
\hline $\mathrm{Cu}-\mathrm{SA} / \mathrm{SNC}$ & 1 & 220 & Energy Environ. Sci. 2019, 12, 3508 \\
\hline $\mathrm{Cu} \mathrm{SAC}$ & 2 & 196 & J. Mater. Chem. A 2019, 7, 16690 \\
\hline
\end{tabular}

